\title{
EFFECTIVENESS OF ULTRASOUND MEASURED URINARY BLADDER WALL THICKNESS AS A = DIAGNOSTIC AND FOLLOW UP TOOL IN MEN WITH BLADDER OUTLET OBSTRUCTION
}

\author{
MOHAMMAD KHAIRUZZAMAN ${ }^{1}$, MUHAMMAD HUMAYUN KABIR ${ }^{2}$, TANVIR AHMED ${ }^{3}$, SYED ALFASANI $^{4}$, \\ MD. SHARIFUL ISLAM ${ }^{5}$, M A SALAM ${ }^{6}$
}

\begin{abstract}
Aim: The present study was undertaken with the aim to standardize ultrasound measured urinary bladder wall thickness (UMUBWT) as an additional routine noninvasive test to assess the bladder outflow obstruction (BOO) and to monitor the therapeutic effects of BOO in follow-up after surgical correction of obstruction.

Methods: This is an interventional study (pretest-posttest type of clinical trial) conducted between December 2012 to May 2015 where sample size was 55 and sampling technique was purposive. In BOO patient transabdominal sonography was performed using a 7.5 $\mathrm{MHz}$. probe. The thickness of the anterior bladder wall at the midline was measured in both preoperative and postoperative period ( three months after operation) at 3 points approximately $1 \mathrm{~cm}$ apart and the average value was recorded.
\end{abstract}

Results: In this study age range was 21-73 years with mean $\pm S D$ of age was $48.76 \pm 15.08$ years. In BOO patient preoperative UMUBWT was $0.51 \pm 0.16 \mathrm{~cm}$ and which reduced to $0.26 \pm 0.05 \mathrm{~cm}$ three months after surgical correction of obstruction.

Conclusion: UMUBWT is a noninvasive, cheap and easily available additional diagnostic tool for detecting $\mathrm{BOO}$ as well as it can measure the therapeutic effects in postoperative period.

Bangladesh J. Urol. 2019; 22(2): 188-193

\section{Introduction:}

It is a well known fact that infravesical obstruction is followed by compensatory hypertrophy of bladder detrusor in men[1,2] and experimental animals, such as rats[3,4], rabbits[5,6] and dogs[7]. Bladder wall thickness increases due to smooth muscle hypertrophy and deposition of connective tissue[8].

1. Assistant Professor, Shaheed Tajuddin Ahmed Medical College, Gazipur.

2. Assistant Professor, Shaheed Tajuddin Ahmed Medical College, Gazipur.

3. Assistant Professor, Colonel Abdul Malek medical college, Manikgonj.

4. Assistant Professor, Sheikh Hasina Medical College, Jamalpur.

5. Assistant Professor, Shaheed Tajuddin Ahmed Medical College, Gazipur.

6. Assistant Professor, Shaheed Tajuddin Ahmed Medical College, Gazipur.

Correspondences: Mohammad Khairuzzaman, Assistant Professor, Shaheed Tajuddin Ahmed Medical College, Gazipur.

Received: 05 February 2019
Sonographic measurements of the bladder wall have shown a low intra- and inter-observer variability, which makes this technique suitable for the routine use in patient[9].

Urodynamic studies still remain the 'gold standard' for diagnosis of infravesical obstruction ${ }^{9}$. Assessment of the urinary bladder wall thickness by ultrasound has been shown to be sensitive and non-invasive tool for assessing the infravesical obstruction[10].

Though now a days pressure flow studies are recognized as the gold standard for the diagnosis of bladder outflow obstruction, their clinical use is limited due to invasive nature of the procedure[11] and limited availability, and ultrasound estimated bladder wall thickness can predict bladder outflow obstruction in a non-invasive way[12].

So in view of an simple auxiliary technique in association with other noninvasive investigations of 
Effectiveness of ultrasound measured urinary bladder wall thickness as a = diagnostic and follow up toolin men with bladder

bladder outflow obstruction the present study will be undertaken with the aim to standardize ultrasound estimated bladder wall thickness as an additional routine test to assess the bladder outflow obstruction and to monitor the therapeutic effects of bladder outflow obstruction in follow-up after surgical removal of obstruction.

\section{Material and methods:}

This interventional study was carried out in the department of Urology, Bangabandhu Sheikh Mujib Medical University in the period of December 2012 to May 2015 and the sampling technique was purposive sampling.

Data were collected by observation, interview, review of records and documents. These patients were admitted in urology department through outpatient department after confirmation of diagnosis. In this period of time 55 patients were selected according to inclusion and exclusion criteria. Prior to operation the patients were evaluated by standard history to exclude diabetes mellitus or neurological illness, international prostate symptom score (IPSS) and quality of life index (QoL), digital rectal examination to exclude prostatic carcinoma and examination to exclude neurological problems. A standard investigation protocol consisting of urinalysis and culture, ultrasonography of KUB and prostate with MCC and PVR, serum PSA, Random blood sugar, Serum creatinine, free Uroflowmetry and RGU and MCU, which were repeated 3 months postoperatively as scheduled. Urinalysis and culture were done to exclude urinary tract infection, ultrasonography was done to see size and intravesical protrusion of median lobe, echo-pattern of prostate and measurement of maximum bladder capacity, post void residual urine and bladder wall thickness and intravesical volume at the same time. Serum PSA helps to exclude carcinoma of prostate. Random blood sugar to see glycemic status. Free uroflowmetry was done to see flow rate curve that gives differentiation between static or dynamic obstruction.

In benign enlargement of prostate (BEP) patients transurethral resection of prostate (TURP), in stricture urethra patients optical internal urethrotomy (OIU), in bladder neck hypertrophy $(\mathrm{BNH})$ bladder neck incision (BNI) and in meatal stenosis meatoplasty was done.

Transabdominal sonography was performed with the patient supine. A longitudinal section of the bladder was obtained by scanning the midline of the lower abdomen above the pubic symphysis when bladder is filled with at least $250 \mathrm{ml}$ of urine using a $7.5 \mathrm{MHz}$. probe. The thickness of the anterior bladder wall at the midline was measured at 3 points approximately $1 \mathrm{~cm}$. apart and the average value was recorded.

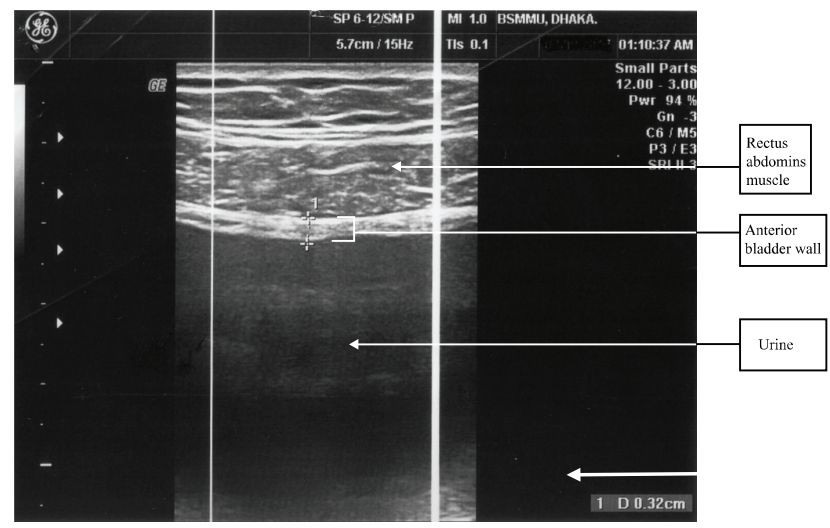

Fig.-1: Ultrasonogram of the anterior wall of urinary bladder.

Hyperechogenic adventitia, hypoechogenic detrusor and hyperechogenic mucosa with submucosa comprise bladder wall and it was measured as 0.31 $\mathrm{cm}$ in the photograph. (Photograph courtesy by Department of Radiology and Imaging, BSMMU)
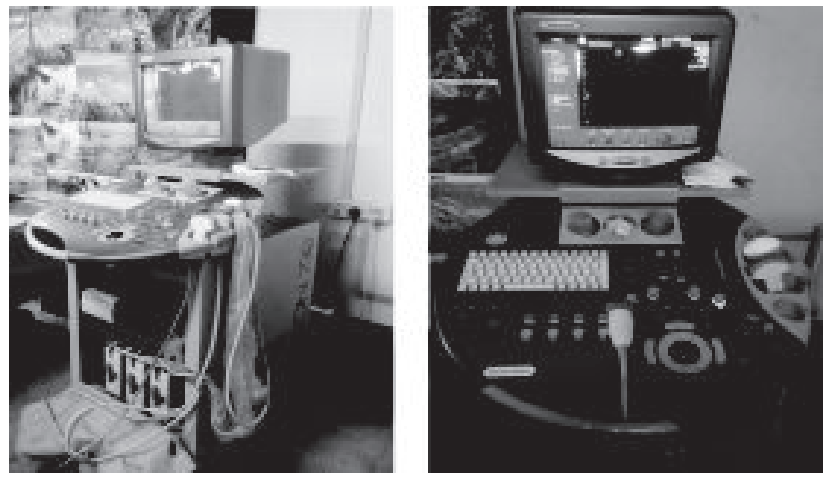

Fig.-2:

VOLUSON 730 ultrasound machine with $7.5 \mathrm{MHz}$ probe in the department of radiology and imaging, Block B, Room no 17 (Photograph courtesy by Department of Radiology and Imaging, BSMMU).

\section{Results:}

This was an interventional study conducted in the department of Urology, BSMMU. Data were analyzed and results are below: 


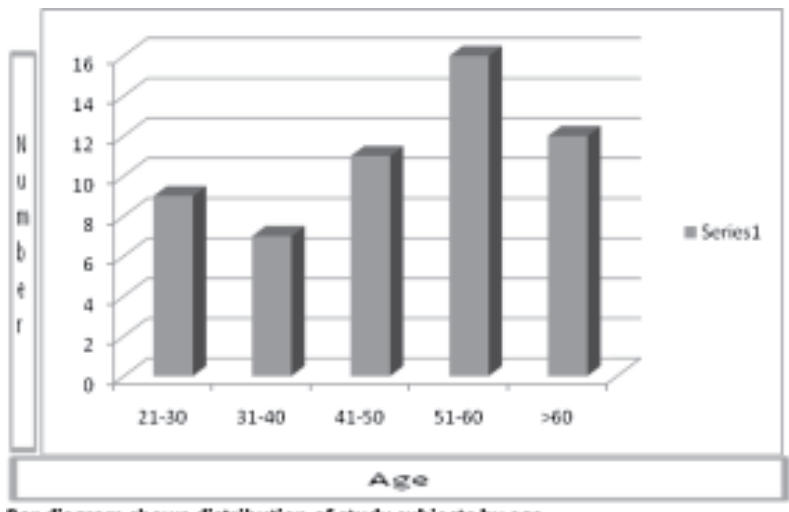

Bar diagram shows distribution of study subjects by age.

Fig.-3: Distribution of study subjects by age.

Bar diagram shows distribution of study subjects by age.

In this study age range was 21-73 years with msean \pm SD of age was $48.76 \pm 15.08$ years. Most of the subjects [16 $(29.1 \%)]$ were in age group $51-60$ years followed by $12(21.8 \%)$ were in age group $>60$ years, $11(20 \%)$ were in age group 41-50 years, $9(16.4 \%)$ were in age group $21-30$ years and $7(12.7 \%)$ were in age group 31-40 years

\section{Disease distribution}

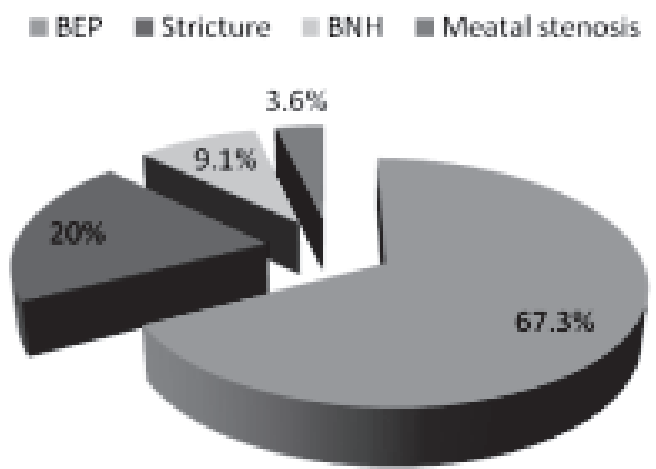

Fig.-4: Distribution of study subjects by disease.

BEP: Benign enlargement of prostate, $\mathrm{BNH}$ : Bladder neck hypertrophy

Pie chart shows distribution of study subjects by disease.

In this study most of the subjects $37(67.3 \%)$ had benign enlargement of prostate followed by $11(20 \%)$ had urethral stricture, $5(9.1 \%)$ had bladder neck hypertrophy and $2(3.6 \%)$ had meatal stenosis.

Table I:

Maximum urinary flow rate (Qmax) of study subjects in pre-operative and post-operative group:

\begin{tabular}{|c|c|c|c|c|}
\hline \multirow[b]{2}{*}{ Group } & \multicolumn{2}{|c|}{ Group } & \multirow[b]{2}{*}{$\begin{array}{c}P \\
\text { value }\end{array}$} & \multirow[b]{2}{*}{$\begin{array}{r}\text { Test } \\
\text { done }\end{array}$} \\
\hline & $\begin{array}{c}\text { Pre-operative } \\
\text { Mean } \pm \text { SD }(\mathrm{ml} / \mathrm{s})\end{array}$ & $\begin{array}{c}\text { Post-operative } \\
\text { Mean } \pm \text { SD }(\mathrm{ml} / \mathrm{s})\end{array}$ & & \\
\hline Overall & $8.74 \pm 3.64$ & $23.52 \pm 6.51$ & 0.0001 & $Z$ test \\
\hline BEP & $10.17 \pm 3.46$ & $24.04 \pm 5.97$ & 0.0001 & $Z$ test \\
\hline Stricture urethra & $5.37 \pm 1.63$ & $22.39 \pm 8.30$ & 0.001 & T test \\
\hline $\mathrm{BNH}$ & $7.44 \pm 1.22$ & $22.76 \pm 5.75$ & 0.002 & T test \\
\hline Meatal stenosis & $4.05 \pm 1.06$ & $22.00 \pm 12.30$ & 0.309 & T test \\
\hline
\end{tabular}

BEP: Benign enlargement of prostate, BNH: Bladder neck hypertrophy

In this study mean \pm SD of overall Qmax in pre-operative and post-operative groups were $8.74 \pm 3.64 \mathrm{ml} / \mathrm{s}$ and $23.52 \pm 6.51 \mathrm{ml} / \mathrm{s}$ respectively. Mean \pm SD of Qmax of BEP for pre-operative and post-operative groups were $10.17 \pm 3.46 \mathrm{ml} / \mathrm{s}$ and $24.04 \pm 5.97 \mathrm{ml} / \mathrm{s}$ respectively. Mean $\pm S D$ of $Q$ max of urethral stricture for pre-operative and post-operative group were $5.37 \pm 1.63 \mathrm{ml} / \mathrm{s}$ and $22.39 \pm 8.30 \mathrm{ml} / \mathrm{s}$ respectively. Mean $\pm \mathrm{SD}$ of Qmax of bladder neck hypertrophy for pre-operative and post-operative groups were $7.44 \pm 1.22 \mathrm{ml} / \mathrm{s}$ and $22.76 \pm 5.75 \mathrm{ml} / \mathrm{s}$ respectively. Mean \pm SD of Qmax of meatal stenosis for pre-operative and post-operative group were $4.05 \pm 1.06$ and $22.00 \pm 12.30$ respectively. 


\section{2(2) 2019}

Effectiveness of ultrasound measured urinary bladder wall thickness as a = diagnostic and follow up toolin men with bladder

Table II

Post void residue of study subjects in pre-operative and post-operative group:

\begin{tabular}{lcccc}
\hline & \multicolumn{2}{c}{ Group } & & Test \\
\cline { 2 - 3 } Group & Pre-operative & Post-operative & P value & done \\
\hline Overall & $111.98 \pm 45.70$ & $17.25 \pm 10.58$ & 0.0001 & Z test \\
BEP & $107.16 \pm 36.26$ & $18.73 \pm 10.63$ & 0.0001 & Z test \\
Stricture urethra & $104.00 \pm 55.11$ & $17.27 \pm 11.50$ & 0.001 & T test \\
BNH & $151.00 \pm 58.32$ & $9.80 \pm 5.93$ & 0.005 & T test \\
Meatal stenosis & $147.50 \pm 312.02$ & $8.50 \pm 0.71$ & 0.041 & T test \\
\hline
\end{tabular}

BEP: Benign enlargement of prostate, BNH: Bladder neck hypertrophy

Mean \pm SD of overall PVR in pre-operative and post-operative groups were $111.98 \pm 43.70 \mathrm{ml}$ and $17.25 \pm 10.58 \mathrm{ml}$ respectively. Mean \pm SD of PVR of BEP for pre-operative and post-operative group were $107.16 \pm 36.26 \mathrm{ml}$ and $18.73 \pm 10.63 \mathrm{ml}$ respectively. Mean \pm SD of PVR of urethral stricture for pre-operative and post-operative group were $104.00 \pm 55.11 \mathrm{ml}$ and $17.27 \pm 11.50 \mathrm{ml}$ respectively. Mean \pm SD of PVR of bladder neck hypertrophy for pre-operative and post-operative group were $151.00 \pm 58.32 \mathrm{ml}$ and $9.80 \pm 5.93 \mathrm{ml}$ respectively. Mean $\pm \mathrm{SD}$ of PVR of meatal stenosis for pre-operative and post-operative group were $147.50 \pm 12.02 \mathrm{ml}$ and $8.50 \pm 0.71 \mathrm{ml}$ respectively.

Table III

Urinary bladder anterior wall thickness of study subjects in pre-operative and post-operative group:

\begin{tabular}{lcccc}
\hline & \multicolumn{2}{c}{ Group } & & Test \\
Group & Mean \pm SD $(\mathrm{cm})$ & Mean \pm SD $(\mathrm{cm})$ & & done \\
\hline Overall & $0.51 \pm 0.16$ & $0.26 \pm .05$ & 0.0001 & Z test \\
BEP & $0.52 \pm 0.17$ & $0.26 \pm 0.05$ & 0.0001 & Z test \\
Stricture urethra & $0.48 \pm 0.14$ & $0.28 \pm 0.03$ & 0.001 & T test \\
BNH & $0.48 \pm 0.14$ & $0.25 \pm 0.06$ & 0.002 & T test \\
Meatal stenosis & $0.48 \pm 0.13$ & $0.23 \pm 0.01$ & 0.05 & T test \\
\hline
\end{tabular}

BEP: Benign enlargement of prostate, BNH: Bladder neck hypertrophy

Mean \pm SD of overall anterior wall thickness in preoperative and post-operative groups were $0.51 \pm 0.16$ $\mathrm{cm}$ and $0.26 \pm 0.05 \mathrm{~cm}$ respectively. Mean $\pm \mathrm{SD}$ of anterior wall thickness of BEP for pre-operative and post-operative group were $0.52 \pm 0.17 \mathrm{~cm}$ and $0.26 \pm$ $0.05 \mathrm{~cm}$ respectively. Mean $\pm \mathrm{SD}$ of anterior wall thickness of urethral stricture for pre-operative and post-operative groups were $0.48 \pm 0.14 \mathrm{~cm}$ and $0.28 \pm$ $0.03 \mathrm{~cm}$ respectively. Mean \pm SD of anterior wall thickness of bladder neck hypertrophy for pre-operative and post-operative group were $0.48 \pm 0.14 \mathrm{~cm}$ and 0.25 $\pm 0.06 \mathrm{~cm}$ respectively. Mean $\pm \mathrm{SD}$ of anterior wall thickness of meatal stenosis for pre-operative and postoperative group were $0.48 \pm 0.13 \mathrm{~cm}$ and $0.23 \pm 0.01$ $\mathrm{cm}$ respectively.

\section{Discussion:}

In the past, bladder hypertrophy resulting from IVO was evaluated from endoscopic and radiographic findings, such as trabecular formation, but had the drawback of being invasive. Though AUA symptom index for $\mathrm{BPH}$ has high correlation with magnitude of urinary symptoms, but it lacks specificity. UFM though being a 
non-invasive tool has its shortcomings and cannot as a single test distinguish between IVO and impaired detrusor contractility. Although pressure flow study is the only method of knowing the presence or absence of IVO, invasive nature of the procedure limits its routine application[1].

Since the introduction of ultrasound, several investigators, using transabdominal scanning, have reported findings of hypertrophy in the bladder detrusor in patients with infravesical obstruction[4].

Ultrasound imaging is dependent on the frequency of the ultrasound waves, the higher the frequency, the better the resolution of the image but the lower the depth of penetration[5]. Suggested that it is necessary to use high frequency ultrasound arrays (7.5 MHz or higher) with an enlargement function of the ultrasound picture for precise measurement of detrusor wall thickness[6].

Basic knowledge about changes of the human bladder as a result of bladder outflow obstruction (BOO) was obtained from experimental animals in which it was proved that bladder wall became thick thus bladder weight increased in infravesical obstruction (IVO) and it became normal after relief of obstruction. This study was conducted depending on that knowledge and aim was to measure pre-operative and post-operative bladder weight to standardize ultrasound estimated bladder wall thickness as a non-invasive diagnostic tool. This was an interventional study where sample size was 55 and ultrasound estimated bladder wall thickness measured in pre-operative and post-operative ( 3 months after operation) group of bladder outflow obstruction.

In this study age range was 21-73 years with msean $\pm S D$ of age was $48.76 \pm 15.08$ years. Most of the subjects [16 $(29.1 \%)]$ were in age group 51-60 years followed by $12(21.8 \%)$ were in age group $>60$ years. In this study most of the subjects $37(67.3 \%)$ had benign enlargement of prostate followed by $11(20 \%)$ had urethral stricture, $5(9.1 \%)$ had bladder neck hypertrophy and $2(3.6 \%)$ had meatal stenosis.

Overall Qmax increased from pre-operative 8.74 \pm 3.64 $\mathrm{ml} / \mathrm{s}$ to post-operative $23.52 \pm 6.51 \mathrm{ml} / \mathrm{s}$ which was statistically significant $(p=0.0001)$. But in meatal stenosis Qmax change is not satistically significant most probably due to small sample size ( sample size was 2).

Overall PVR reduced from pre-operative mean \pm SD 111. $98 \pm 43.70 \mathrm{ml}$ to post-operative mean \pm SD $17.25 \pm 10.58$ $\mathrm{ml}$ which was statistically significant $(\mathrm{p}=0.0001)$.

Overall anterior bladder thickness reduced from mean $\pm S D 0.51 \pm 0.16 \mathrm{~cm}$ to post-operative mean $\pm S D$ $0.26 \pm 0.05 \mathrm{~cm}$ which was statistically significant $(p=0.0001)$.

Ultrasound estimated bladder wall thickness is a good non-invasive diagnostic tool for diagnosis of infravesical obstruction (IVO) as well as it showed good promise in follow up of bladder outflow obstruction (BOO). Having lot of limitations of this study it can be used as a tamplet for further research in this field.

\section{Conclusion:}

Since the introduction of ultrasound it has become a prominent diagnostic modality in the evaluation of urological disease. Ultrasound estimated bladder wall thickness is a reliable tool for predicting bladder outflow obstruction. It is also useful in monitoring therapeutic effects in man with urinary symptoms due to bladder outflow obstruction because of significant co-relation with the degree of obstruction. Considering its noninvasiveness and low cost of ultrasound estimated bladder wall thickness is promising as an auxiliary technique for diagnosis and follow up in post operative period of bladder outflow obstruction. But further comparison with urodynamic study is needed to determine whether it can replace pressure flow studies or not.

\section{Referrences:}

1. Swinney, J.: The management of the decompensated bladder, Brit. J. Urol.,30: 423, 1958

2. Gosling, J. A. and Dixon, J. S.: Detrusor morphology in relation to bladder outflow obstruction and isstability. In: Benign Prostatic Hypertrophy, Edited by F. Hinman, Jr. New York: Springer Verlag, pp. 666-671, 1983

3. Uvelius, B. and Mattiasson, A.: Collagen content in the rat urinary bladder subjected to infravesical outflow obstruction. J. Urol., 132: 587, 1984

4. Saito, M., Ohmura, M. and Kondo, A.: Effects of long-term partial outflow obstruction on bladder function in the rat. Neurourol, Urodynam., 15: 157, 1996

5. Ghoniem, G. M., Regnier, C.H., Biancani, P., Johnson , L. and Susset, J. G.: Effect of vesical outlet obstruction on detrusor contractility and passive properties in rabbits, J. Urol., 135: 1284, 1986 
Effectiveness of ultrasound measured urinary bladder wall thickness as a = diagnostic and follow up toolin men with bladder

6. Malkowicz, S. B., Wein, A.J., Elbadawi, A., van Arsdalen, K., Ruggieri, M. R. and Levin, R. M.: Acute biochemical and functional alterations in the partially obstructed rabit urinary bladder. J. Urol., 136: 1324, 1986

7. Kondo, A. and Susset, J. G.: Collagen content in detrusor muscle and ratio of bladder weight to body weight. Acta Urol. Jap., !9: 683, 1973

8. Uvelius B, Persson L, Mattiasson A. (1984). Smooth muscle cell hypertrophy and hyperplasia in the rat after short-time infravesical outflow obstruction. J Urol, 131: 173-6

9. Wani S, Hamid A, Kishore MG, Malviya V, Dwivedi US, Singh PB (2003) Color doppler ultrasonography: Its role in detection and treatment outcome in infravesical obstruction,
Indian Journal of Urology, vol. 19, no. 2, pp. 109112.

10. Kojima M, Inui E, Ochiai A, Naya $Y$, Ukimura O and Watanabe H (1997) Noninvasive quantitative estimation of infravesical obstruction using ultrasonic measurement of bladder weight, The Journal of Urology, vol. 157, February, pp. 476479.

11. Paul DK, Bora V, Shukla RC, Dwivedi US, Singh PB (2000) Ultrasound estimated bladder weight: Its role to detect and follow-up of bladder outflow obstruction, Indian Journal of Urology, vol. 16, no. 2, pp. 118-121.

12. Kojima $M$, Inui $E$, Ochiai $A$, Naya $Y$, Ukimura $O$ and Watanabe $\mathrm{H}$ (1996) ultrasonic estimation of bladder weight as a measure of bladder hypertrophy in men with infravesical obstruction: a preliminary report, Urology, vol 47, pp 942-947. 